\title{
First study of equine cryptosporidiosis in asymptomatic traction horses in Peshawar Khyber Pakhtunkhwa Pakistan
}

Naimat Ullah Khan ${ }^{1 *}$, Samia Sultan², Ihasan Ullah ${ }^{3}$, Mian Saeed Sarwar ${ }^{1}$, Tahir Usman ${ }^{1}$, Hazrat Ali ${ }^{1}$, Anwar Ali ${ }^{4}$, Azmatullah Khan ${ }^{5}$, Fazli Rabbani ${ }^{1}$, Abdul Razzaq ${ }^{6}$ and Munib Hussain ${ }^{7}$

1. College of veterinary sciences and animal Husbandry, Abdul Wali Khan University Mardan, KPK-Pakistan

2. Department of Zoology, Abdul Wali Khan University Mardan-Pakistan

3. Department of Animal Health, Agriculture University Peshawar-Pakistan

4. Veterinary Research Institute, Peshawar, KPK-Pakistan

5. Department of Livestock and Dairy Development Bannu KPK-Pakistan

6. Animal Sciences Division, Pakistan Agriculture Research council, Islamabad-Pakistan

7. Animal sciences institute NARC Islamabad-Pakistan

*Corresponding author's email: naimatullahkhan19@yahoo.com

Citation

Naimat Ullah Khan, Samia Sultan, Ihasan Ullah, Mian Saeed Sarwar, Tahir Usman, HazratAli, Anwar Ali, Azmatullah Khan, Fazli Rabbani, Abdul Razzaq and Munib Hussain. First Study of Equine Cryptosporidiosis in Asymptomatic Traction Horses in Peshawar Khyber Pakhtunkhwa Pakistan. Pure and Applied Biology. Vol. 9, Issue 1, pp396-402. http://dx.doi.org/10.19045/bspab.2020.90044

Received: 16/08/2019

Revised: 28/10/2019

Accepted: 05/11/2019

Online First: 00/00/2019

\section{Abstract}

The present project was conducted to explore the prevalence of Cryptosporidium species in equines along with associated risk factors (age, sex, month wise). Overall 384 samples were collected randomly from apparently healthy horses from different stations in district Peshawar. As a result, the overall prevalence of equine cryptosporidiosis was $11.97 \%(46 / 384 \times 100)$ screened by microscopic examination after acid fast staining. According to the age wise equine cryptosporidiosis, the highest prevalence $(16.96 \%)$ was recorded in young equines at the age of $(<1-5$ years) while the lowest $(9.92 \%)$ in adult equines at the age of $(\geq 6-10$ years) and observed significant $(p<0.001)$ association. The highest sex wise equine cryptosporidiosis was recorded in male horses $(13.76 \%)$ followed by female horses $(10.97 \%)$ and statistically insignificant association $(p<0.132)$ was recorded. According to the month wise prevalence, the highest prevalence was record in month of June (23.07\%) followed by April (16.12\%), July (15.62\%), September (14.70\%), October (13.79\%), August (10.71\%), January (10.71\%), March (8.82\%), February (8.69\%) while the lowest in December $(6.06 \%)$ and statistically significant association $(p<0.05)$ was recorded. As a result, it was concluded that asymptomatic horses were responsible for high excretion of Cryptosporidium oocysts that continuously contaminate the environment as well as different sources of drinking water used for humans and animals in rural areas.

Keywords: Cryptosporidiosis; Equines; Risk factors; Prevalence; Cryptosporidium; Zoonotic

\section{Introduction}

Cryptosporidium species are major enteric protozoan parasites carrying both medical and veterinary importance affecting a wide range of humans and animals globally [1]. This protozoan has been considered as the primary enteric pathogen causing gastrointestinal problems in humans and 
animals [2].Among different species of Cryptosporidium, C. parvum has been recognized as primary enteric pathogen causing huge economic losses in humans and animals [3]. Cryptosporidium parvum is the main specie affecting the humans and equines. The Cryptosporidium infections are commonly linked with sign of diarrhea in man and animals [4]. This organism has two form of life cycles such as "zoonotic and anthroponotic form" [5]. It is transmitted either by drinking of contaminated water or ingestion of contaminated vegetables or food.Cryptosporidiosis leads to enteritisresulting in diarrhoea. The severity of the diarrhoeic condition has been ranked from self - limiting to lethal diarrhea [6]. Equine cryptosporidiosis plays a vital role as a potential source of zoonotic infection to young and adults [7]. Clinically some animals are suffering from cryptosporidiosis but apparently look healthy with no clinical signs; such hosts play a potential role for spread of Cryptosporidium infection. All those animals suffering from Cryptosporidium infection mainly suffer from dysentery or presence of mucous in stool with heavy production of gas [8]. It has been estimated that Cryptosporidium infection causes $30-50 \%$ mortality in young patients and it has been recorded second most common cause of diarrhea as well as death after rotavirus infection in kids globally [9]. Currently a major morbidity and mortality has been reported in humans are suffering with diarrhea infected by Cryptosporidium parvum after drinking of contaminated water $[10,11]$. The domestic and wild animals play a vital role in contamination of drinking water used for humans consumption. Among domestic animals equines access should be minimized to different sources of surface water such as rivers, streams, canals and ponds etc $[10,12,13]$. About equine cryptosporidiosis, limited informations are available in our country although it has been reported in different regions of the world, linked with diarrhoea in equines $[13,14]$. The plan of the study was to explore the prevalence of equine cryptosporidiosis in apparently healthy equines responsible for human

\section{Materials and methods Ethical approval}

This study was properly approved by University Ethical Committee (UEC). First took the permission from the horse owner then fecal materials were collected with the help of disposable gloves after proper lubrication and restraining. Necessary veterinary services were also provided free of cost along with free medication (deworming).

\section{Study area}

The Peshawar is the capital of Khyber Pakhtunkhwa, Pakistan. The latitude of Peshawar is 34.025917, and the longitude is 71.560135. The Peshawar coordinates at $34^{\circ}$ 1' 33.3012" $\mathrm{N}$ and 71 ${ }^{\circ} 33^{\prime}$ 36.4860" E. Peshawar is located at elevation of 317 meters height (1040ft) from sea level.

\section{Selection criteria of animals}

The horses were selected on the basis of simple random sampling technique. The horses were selected based on some clinical signs such as mild form of diarrhoea or without diarrhoea and poor response to routine antidiarrheal drugs. Both sexes and different age groups of horses were selected regardless to breed. Age was estimated by examination of teeth.

\section{Study period}

This study was continued for a period of 12 months (January, 2018 to December, 2018). Horses were selected randomly from 20 different stations where horses were used for transport or carriage purpose.

\section{Sample size}

The sample size was calculated according to the following formula designated by [15].

$\mathrm{n}=\mathrm{Z}^{2}(\mathrm{P})(1-\mathrm{P}) / \mathrm{d} 2$

Where: 
$\mathrm{n}=$ stands for sample size, $\mathrm{Z}$ means $\mathrm{Z}$ value indicating (confidence level 95\%); $\mathrm{P}$ means prevalence (i.e. $50 \%, \mathrm{p}=0.5$ ) where $\mathrm{d}$ stands for precision (i.e. $5 \%, d=0.05$ ) $n=384$

\section{Epidemiological exploration Questionnaire}

Prepared a questionnaire where the different informations were entered at the time of visiting for the purpose of sampling. These informations were include name of the owner with address, age of the horse $(\leq 1-5$ years, $\geq$ 6- 10 years), sex of the horse (Male or Female), different months for sampling, previous treatment history of deworming, source of drinking water either deep or surface water such as well water and river water, month of sampling, diarrheic or nondiarrheic, stall feeding or grazing and stable is hygienic or non- hygienic.

Collection and shipping of fecal materials

A total of 384 samples were collected from 20 different stations of horses in Peshawar. Approximately 8-12 g fecal samples were either directly taken either from the rectum or fresh passed feces. After collection the feces were stored in clear plastic bottles containing $10 \%$ formalin (1 part feces: 4 parts formalin). All the samples were properly closed and labeled after collection.

\section{Experimental site}

All the samples were shipped to Parasitology Laboratory where stored at $4 \mathrm{C}^{0}$ till examination.

\section{Laboratory analysis of fecal samples}

Fecal samples were processed by a technique known as centrifugation-sedimentation technique, reported by [16]. 03 gram feces were weighed by electric balance. After weighing, dissolved in water to obtain homogenized solution and centrifuged at $1500 \mathrm{rpm}$ for 2 minutes. Removed supernatant after centrifugation and resuspended in flotation solution (44\%ZnSO4).Again the solution was centrifuged, removed supernatant and examined sediment under microscope after staining by modified Ziehl- Neelsen technique

Modified zeihl- neelsen staining technique Made a thin smear from the sediments and stained by modified Zeihl-Neelsen staining technique as reported by [17].

Microscopic examination of stained slides

All the slides were examined with the help of light microscope at $40 \mathrm{x}$ and $100 \mathrm{x}$ magnification for detection of Cryptosporidium oocysts as mentioned by [17]. The oocysts appeared bright red in color. All the samples were considered positive where even one oocyst was identified. Cryptosporidium oocyst appeared as bright red granules on a blue-green background in MZN stained fecal smears.

Identification of Cryptosporidium oocysts Cryptosporidium oocysts were recognized on the basis of size, shape and the identification key mentioned by [18].

By using the following formula the infection rate was calculated;

\section{Prevalence $\%$ Rate $=\underline{\text { Total number of horses infected } \times 100}$ \\ Total number of horses examined}

Prepared a single slide from each fecal sample and examined under microscope. If at least single oocyst was seen per slide then such animal was considered a positive case for cryptosporidiosis.

\section{Statistical analysis}

The collected data were analyzed by conventional percentage and average analysis and chi square analysis to achieve the objectives of the study. 
Results

Overall prevalence

In the present study, the overall prevalence of

equine cryptosporidiosis was $11.97 \%$
$(46 / 384 \times 100) \quad$ under field conditions screened by microscopic examination after staining in district Peshawar, KPK Pakistan as presented in (Table 1).

Table 1. Overall prevalence of cryptosporidiosis in equines

\begin{tabular}{|c|c|c|c|}
\hline Factors & $\begin{array}{c}\text { Total horses } \\
\text { examined }\end{array}$ & $\begin{array}{c}\text { Total number of positive } \\
\text { cases }\end{array}$ & Overall Prevalence (\%) \\
\hline $\begin{array}{c}\text { Equine } \\
\text { cryptosporidiosis }\end{array}$ & 384 & 46 & 11.97 \\
\hline
\end{tabular}

\section{Age wise prevalence}

In the present study, the age wise equine cryptosporidiosis was also reported where the highest prevalence (16.96\%) was determined in young equines at the age of $(<1-5)$ years while lowest prevalence $(9.92 \%)$ was observed in adult equines at the age of $(\geq 6$ 10) years as presented by (Table 2) and statistically significant $(\mathrm{p}<0.001)$ association was observed.

Table 2. Age wise prevalence of cryptosporidiosis in equines

\begin{tabular}{|c|c|c|c|c|}
\hline Factor(Age) & Total horses examined & Positive cases & Prevalence (\%) & P. Value \\
\hline Young $(<1-5$ years $)$ & 112 & 19 & $16.96^{\mathrm{a}}$ & \multirow{2}{*}{$\mathrm{P}<0.001^{*}$} \\
\hline Adult( $(\geq 6-10$ years $)$ & 272 & 27 & $9.92^{\mathrm{b}}$ & \\
\hline
\end{tabular}

Sex wise prevalence

Similarly sex wise equine cryptosporidiosis was also studied where the highest prevalence was recorded in male horses
$(13.76 \%)$ followed by female horses $(10.97 \%)$ as shown by (Table 3) and statistically insignificant association $(p<0.132)$ was observed.

Table 3. Sex wise prevalence of cryptosporidiosis in equines

\begin{tabular}{|c|c|c|c|c|}
\hline Factor (sex) & Total horses examined & Positive cases & Prevalence (\%) & P. value \\
\hline Male & 138 & 19 & $13.76^{\mathrm{a}}$ & \multirow{2}{*}{$\mathrm{p}<0.132$} \\
\hline Female & 246 & 27 & $10.97^{\mathrm{ab}}$ & \\
\hline
\end{tabular}
$(\mathrm{P}>0.05)$ while carrying different superscripts, are differ significantly at $(\mathrm{P}<0.05)$

\section{Month wise prevalence}

Presently the month wise prevalence was also recorded where the highest prevalence was record in the month of June (23.07\%) followed by April (16.12\%), July (15.62\%), September (14.70\%), October (13.79\%),
August(10.71\%), January(10.71\%), March (8.82\%), February $(8.69 \%)$ while the lowest in the month of December $(6.06 \%)$ and statistically significant association $(p<0.05)$ was found (Table 4). 
Table 4. Month wise prevalence of cryptosporidiosis in equines

\begin{tabular}{|c|c|c|c|c|}
\hline Factors( Months) & Examined cases & Positive cases & Prevalence (\%) & P. Value \\
\hline January & 28 & 3 & $10.71^{\mathrm{n}}$ & \\
\hline February & 23 & 2 & $8.69^{\mathrm{nm}}$ & \\
\hline March & 34 & 3 & $8.82^{\mathrm{nm}}$ & \\
\hline April & 31 & 5 & $16.12^{\mathrm{b}}$ & \multirow{2}{*}{$\mathbf{p}<\mathbf{0 . 0 5}^{*}$} \\
\hline May & 41 & 4 & $9.75^{\mathrm{n}}$ & \\
\hline June & 26 & 6 & $23.07^{\mathrm{a}}$ & \\
\hline July & 32 & 5 & $15.62^{\mathrm{bc}}$ \\
\hline August & 37 & 4 & $10.81^{\mathrm{n}}$ & \\
\hline September & 34 & 5 & $14.70^{\mathrm{bcd}}$ & \\
\hline October & 29 & 4 & $13.79^{\mathrm{bcdf}}$ & \\
\hline November & 36 & 3 & $8.33^{\mathrm{nm}}$ & \\
\hline December & 33 & 2 & $6.06^{\mathrm{ml}}$ & \\
\hline
\end{tabular}

$\mathrm{a}$, ab, abc, bcd, bcdf, n, nm, ml are themean values if they are carryingsimilar superscript within the same row then differ nonsignificantly $(\mathrm{P}>0.05)$ while carrying different superscripts, are differ significantly at $(\mathrm{P}<0.05)$

\section{Discussion}

Overall prevalence of equine cryptosporidiosis

In the present study, the overall prevalence of equine cryptosporidiosis was $11.97 \%$ $(46 / 384 \times 100)$ under field conditions screened by microscopic examination after staining in district Peshawar, KPK Pakistan. Our findings are in line with [19] who reported 3.5 to $11.5 \%$ equine cryptosporidiosis. [20] reported $15.8 \%$ cryptosporidial infection after examination 221 fecal samples from 18 villages of Urmia, NW. Iran. Our results are lower than [20]. Some researcher recorded little higher prevalence than our findings such as Butty reported $27.10(\%)$ prevalence in horses. .However some researchers reported lower prevalence than our findings in different countries such as Poland, Germany and USA, ranging from 0.33 to $9.4 \%$.In our study, the overall rate of cryptosporidial infection in horses was higher than that reported by other authors from Germany, Poland and Texas and Colorado, USA, which ranged from $0.33-9.4 \%$ [21].

However our results are lower than the findings reported by other authors such as 17 to $100 \%$ reported by $[3,8]$.The differences in the percentage of infection in the months may be related to different factors such as number of samples, environmental condition, age, sex, immunity status, stress factor etc.

Equine cryptosporidiosis associated with age

In the present study, the age wise equine cryptosporidiosis was also reported where the highest prevalence $(16.96 \%)$ was determined in young equines at the age of $(\leq 1-5)$ years while lowest prevalence $(9.92 \%)$ was observed in adult equines at the age of $(\geq 6$ 10) years as presented in(Table 2) and statistically significant $(\mathrm{p}<0.001)$ association was observed. Similar findings were also reported by [20] who observed highest prevalence $(20 \%)$ at the age of $<5$ while lower at the age of $\geq 5$ years (13.69\%).Our results are lower than reported by [22] who reported highest prevalence at the age of 5-6 years $(34.38 \%)$ than $7-8$ years( $27.59 \%)$ however highest prevalence was recorded at early age .The high prevalence in young animals may be due to immature immune status, poor hygienic conditions, sampling technique and nature of life either domestic or feral. 
Equine cryptosporidiosis associated with sex

In the present study sex wise equine cryptosporidiosis was also studied where the highest prevalence was recorded in male horses $(13.76 \%)$ followed by female horses $(10.97 \%)$. and statistically insignificant association ( $p>0.05$ ) was observed. Our results are like [20] who also reported highest prevalence in male $(17.14 \%)$ than female (13.58\%).Furthermore, our gender wise prevalence results are also close to the study of [20]. Our results are higher than [23] who reported $3.7 \%$ prevalence in male and $1.7 \%$ in female. However the highest prevalence was reported in male horses than female.

Equine cryptosporidiosis associated with months

Presently the month wise prevalence was also recorded where the highest prevalence was record in the month of June (23.07\%) followed by April (16.12\%), July (15.62\%), September (14.70\%), October (13.79\%), August (10.71\%), January (10.71\%), May (9.75\%), March (8.82\%), February (8.69\%) while the lowest in the month of December $(6.06 \%)$ and statistically significant association $(p<0.05)$ was found. Our results are close to the findings reported by [22] where similar findings were found in some months of the year such as January (14.29\%: $10.71 \%)$, February (10\%:8.69\%), June (25\%: $23.07 \%)$ and November (12.5\%: 8.33\%).However our results are differ in some other months of the year from [22] such as in March (36.36\%:8.82\%), April (55.56\%:16.12\%), May (23.08\%: 9.75\%), July (25\%: 15.62\%), August (20\%: 10.71\%), September (50\%:14.70\%), October (42.86\%: $13.79 \%)$ and December (15.38\%: 6.06\%). It has been concluded that these variations may be due different hygienic conditions, sample size, immune status of the animals, study design and diagnostic techniques.

\section{Conclusion}

It has been concluded that asymptomatic horses are responsible for high excretion of Cryptosporidium oocysts that continuously contaminate the environment and act as a possible potential source of infection to their handlers (coachmen), children playing in a streets and different sources of water used for drinking purpose where they bath the horses. This study explores the importance of equine cryptosporidiosis and involved in control and prevention of protozoosis.

\section{Authors' contributions}

Conceived and designed the experiments: NU Khan \& S Sultan, Performed the experiments: A Ali, Analyzed the data: T Usman, MS Sarwar \& H Ali, Contributed materials/ analysis/ tool: A Razzaq, I Ullah \& F Rabbani, Wrote the paper: AU Khan \& M Hussain.

\section{Acknowledgments}

We are thankful to the Veterinary Research Institute Peshawar on provision of facilities.

\section{References}

1. Kotloff KL, Nataro JP, Blackwelder WC, Nasrin D , Farag TH \& Panchalingam S (2013). Burden and aetiology of diarrhoeal disease in infants and young children in developing countries (the Global Enteric Multicenter Study, GEMS): a prospective, case-control study. The Lancet 382: 209222.

2. Johsone E, Atwill ER \& Filkin ME (1997). The prevalence of shedding ofCryptosporidium and Giardia spp. based on asingle fecal sample collection from each of 91horses used for backcountry recreation. J Vet Diagn Invest 9: 56-60.

3. Xiao L\& Herd RP (1994). Epidemiology of equine Cryptosporidium and Giardia infections. Equine Vet J 26: 14-17.

4. Dubey JP, Speer CA \& Fayer R (1990). Cryptosporidiosis of man and animals. CRS Pres 48-54.

5. Ong CS, Eisler DC, Goh SH, Tomblin J, Awad EL, Kariem FM, Beard CB \& 
Striepen L (2013). Parasitic infections: time to tackle cryptosporidiosis. Nature News 503: 189-191.

6. Lecherallier MW, Norton WD \& Leek G (1991). Giardia and cryptosporidium sp, in surface water. App Environ Microbiol 57:2610-2616.

7. Da Voodi NMY (2000). The horse source of cryptosporidial infection for human.4th National congress of zoonoses in Iran.Tehran, Iran.

8. Olson MM Thorlakson CL, Deselliers L, Morck DW \& McAllister TA (1997). Giardia and Cryptosporidium in Canadian farm animals. Vet Parasitol 68: 375-381.

9. Stripen K, Tamang, K, Thaddeus K \& Graczyk (2004). Equine $C$. parvuminfections in W. Poland. Parasitol Res 96: 153-157.

10. Kramer MH, Herwaldt BL, Craun GF, Calderon RL \& Juranek DD (1996). Surveillance for waterborne-disease outbreaks-United States, 1993-1994. Morbid.Mortal. Weekly Rep 45: 1-33.

11. Meinhardt PL, Casemore DP \& Miller KB (1996). Epidemiologic aspects of human cryptosporidiosis and the role of waterborne transmission. Epidemiol Rev 18: 118-13.

12. Hayes EB, Matte TD, O'Brien TR, McKinley TW, Logsdon GS, Rose JB, Ungar BLP, Word DM, Pinsky PF, Cummings ML, Wilson MA, Long EG, Hurwitz ES \& Juranek DD (1989). Large community outbreak of cryptosporidiosis due to contamination of a filtered public water supply. $N$ Engl J Med 320: 13721376.

13. Fayer R, Speer CA \& Dubey JP (1997). The general biology of cryptosporidium: In: fay er (ed): Cryptosporidium and cryptosporidiosis, 1-14 CRC press, Boca Raton.

14. Fayer R, Speer CA \& Dubey JP (1998). The general biology of cryptosporidium: Cryptosporidium and cryptosporidiosis, CRC 1-14.
15. Dooho L, Coleman Su, Klei TR, French DD, Chapmann MR \& Corstret RE (1989). Prevalence of Cryptosporidium in equine in Louisiana. Am J vet Res 50: 575-577.

16. Meloni BP \& Tompson RCA (1996). Simplifed methods for obtaining purified oocysts from mice and for growing Cryptosporidium parvumin vitro. $J$ Parasitol 82: 757-762.

17. Casemore DP, Sands RL \& Armstrong (1985).Laboratory diagnosis of Cryptosporidiosis. J Clinical Pathol 38: 1337-1341.

18. Watanabe Y, Kimura K \& Yang Chnd HK (2005). Detection of Cryptosporidium sp. Oocysts and Giardia sp cysts in faucet water samples from cattle and goat farms in Taiwan. $J$ Vet Med Sci 67: 1285- 1287.

19. Anna C, Majewska AE,Solarczyk P, Tamang L, Thaddeus K \& Graczyk K (2004). Equine Cryptosporidium parvum infections in western Poland. Parasitol Res 93: 274-278.

20. Tavassoli M, Sodagar-Skandarabadi M \& Soltanalinejad F (2007). A survey on cryptosporidial infection in horse in Urmia area, northwestern Iran. Iranian $J$ of Vet Res, University of Shiraz 8: 18-22.

21. Cole DJ, Cohen ND, Snowden K \& Smith R (1998). Prevalence of and risk factors for fecal shedding of Cryptosporidium parvum oocysts in horses. J Am Vet Med Assoc 213: 1296-1302.

22. Butty ET (2011). Detection of Cryptosporidium and Giardia doudenalis in equines in Nineveh, Iraq. Iraqi $\mathrm{J}$ of Vet Sci 25: 43-46.

23. Laatamnaa AE, Pavla-Wagnerováb C, Bohumil S, Dana K, Lihua X, R Michael R, John M, Rachid A Meriem A \& Martin K (2015). Microsporidia and Cryptosporidium in horses and donkeys in Algeria: Detection of a novel Cryptosporidium hominissubtype family (Ik) in a horse. Vet Parasitol 208: 135-142. 